\title{
Salvemos las Naciones Unidas
}

\author{
Francisco Javier Ibisate \\ Departamento de Economía \\ UCA, San Salvador
}

\begin{abstract}
RESUMEN: La Organización de las $\mathrm{Na}$ ciones Unidas no es la unica responsable de que se hayan agudizado los tres grandes desafios de "una economía mundial injus$t a$, los desórdenes mundiales y el frecuente desprecio de los derechos bumanos". En la gestación y agudización de estos grandes problemas han participado directamente las cuatro instituciones creadas luego de la Segunda Guerra Mundial: El FMI, el $B M$, la OMC y la ONU. Si estas cuatro instituciones internacionales no ban cumplido con sus objetivos fundacionales bay que preguntarse si existe una causa o un fenómeno común a estas cuatro crisis o quiebras globales.
\end{abstract}

\begin{abstract}
UN is not the only responsible of the increase of the three great challenges of "an unfair world economy, world disorder and the common despise of human rights". The institutions that were created after World War II (IMF, $W B, W T O$ and the $U N)$ are responsible for these problems. It these international organizations have not fulfilled its foundational aims, it is necessary to ask if there is a common cause of phenomenon for these four global crisis.
\end{abstract}

\section{1.) Un amargo discurso de despedida}

Al terminar su segundo mandato como Secretario General de Naciones Unidas, Kofi Annan recuerda que en su primer discurso ante la Asamblea de la ONU había planteado los tres grandes desafíos a enfrentar en 1997: "una economía mundial injusta, los desórdenes mundiales y el frecuente desprecio de los derechos humanos”. Al terminar su segundo mandato, K. Annan confiesa que "los acontecimientos de estos diez años no los han resuelto, sino que los han agudizado. En consecuencia,

\section{1}


nos encontramos actualmente enfrentados a un mundo en el que las divisiones amenazan la noción misma de comunidad internacional sobre la que precisamente reposa esta institución”. (Le Monde, 19 de septiembre de 2006) En la misma fecha, el diario El País dice: "Annan alerta de la división del mundo en su último discurso ante la Asamblea General de la ONU”. "Annan se despide con un amargo discurso". (Rebelión, 21 de septiembre de 2006)

A los tres desafíos iniciales se agrega el desafío mayor. "las divisiones amenazan la noción misma de comunidad internacional”, elegante y amarga expresión de Kofi Annan que, en lenguaje callejero, llamaríamos "la ley de la selva y el orden mundial". Basta recordar el estilo verbal y el contenido agresivo de algunos de los discursos en la presente Asamblea General y, en forma más cruda y agresiva, el conflicto inconcluso del Próximo Oriente. Kofi Annan afirma que el conflicto del Próximo Oriente es el desafío mayor para la seguridad mundial: "Ningún otro conflicto contiene tal carga simbólica y emocional entre personas incluso alejadas del campo de batalla. Mientras los palestinos vivan sin trabajo, expuestos a las cotidianas frustraciones y humillaciones, y mientras los israelitas sean despedazados por bombas explotadas en los autobuses o en salas de baile, las pasiones se seguirán inflamando cada vez más”.

Ahora se está hablando de los posibles sucesores de Kofi Annan; se citan seis nombres para enero de 2007. Pero el problema no es Kofi Annan, como tampoco lo fue su predecesor Boutros Ghali. Incluso tampoco el problema es la propia institución de Naciones Unidas, en cuanto institución. La ONU tiene la misma edad que el Fondo Monetario Internacional, el Banco Internacional de Reconstrucción y Fomento, hoy Banco Mundial, y que el GATT, hoy Organización Mundial del Comercio. Estas tres últimas instituciones han respondido mucho peor a sus objetivos fundacionales, como lo muestra, entre otros autores, Joseph Stiglitz, en su libro El malestar en la globalización. La raíz mayor de la división mundial está en los gobiernos que más cotizan y más controlan estas cuatro instituciones internacionales. Así lo afirmaba hace poco el Premio Nobel de la Paz, Adolfo Pérez Esquivel, al analizar el conflicto palestino-israelí: "Lamentablemente las Naciones Unidas han perdido presencia, coraje y decisiones para poder aportar a la solución del enfrentamiento entre los dos pueblos, situación que pone en riesgo la paz mundial. La ONU fue avasallada por las grandes potencias y la usan cuando responde a sus intereses y no a las necesidades de la huma- 
nidad. Es necesaria una reforma profunda y democratizar sus estructuras y hacerla más operativa y eficaz en bien de los pueblos" (Rebelión, 15 de julio de 2006).

En la apertura de la Cumbre del Milenio de 2001, Kofi Annan dice que "hay que reinventar las Naciones Unidas". Antes de plantear las reformas, presenta algunos de los problemas. Desde la fundación de la ONU la población mundial se ha duplicado: 6.000 millones. También se han multiplicado las guerras y se agrega el fenómeno de las limpiezas étnicas, el problema del medio ambiente, las epidemias del SIDA, malaria, tuberculosis y la creciente marea de la pobreza. El plan de acción del siglo XXI integra el binomio de la deuda externa y la apertura de las fronteras de los países ricos a las exportaciones del Tercer Mundo. "La globalización es muy beneficiosa para algunos y potencialmente beneficiosa para todos, pero sólo si los Estados trabajan conjuntamente para que estos beneficios lleguen a todo su pueblo. En contraste, miles de millones quedarán abandonados a la pobreza y otros países emergentes están a la merced de súbitos cambios económicos (crisis financiera de 1997). Afrontamos desafíos mundiales que nos obligan a trabajar juntos y si esto es cierto en la esfera económica, lo es aún más ante el desafío que representan las matanzas y las guerras”.

Al subrayar los 'objetivos del milenio' se solicita a los 191 países miembros cumplir algunos de los compromisos pactados. "La paz, la seguridad y el desarme" requieren que los Gobiernos "cumplan las decisiones de la Corte Internacional de Justicia de acuerdo a la Carta de Naciones Unidas; deben aportar a la ONU los recursos necesarios para financiar los crecientes servicios a la paz mundial. Se ruega a los países miembros ratificar los estatutos de la Corte Penal Internacional, que juzgue y aplique sanciones por crímenes de guerra, crímenes contra la paz y de lesa humanidad y genocidio, que los tribunales nacionales no puedan o no quieran juzgar. Se solicita una profunda reforma del Consejo de Seguridad, que responda mejor a la nueva estructura geopolítica mundial. "El desarrollo y la erradicación de la pobreza" requieren "un sistema comercial y financiero multilateral, abierto, basado en normas, previsible y no discriminatorio". "La protección de nuestro entorno común” exige que el Protocolo de Kyoto entre en vigor en el año 2002 y se apliquen el Convenio sobre Diversidad Biológica y la Convención de la lucha contra la desertificación. "Derechos humanos, democracia y buen gobierno”, haciendo valer plenamente la Declaración Universal 
de Derechos Humanos. Se agregan "la protección de las personas vulnerables" y "la atención a las necesidades especiales de África".

Son pocos los gobiernos, y menos aún las grandes potencias, que han tomado en serio la ratificación de los estatutos y el cumplimiento de los protocolos, convenios o convenciones entonces pactados, haciendo ilusorios los objetivos del milenio. Hay aquí un problema más global: Naciones Unidas, como institución, no es la única responsable de que se hayan agudizado los tres grandes desafíos de "una economía mundial injusta, los desórdenes mundiales y el frecuente desprecio de los derechos humanos". En la gestación y agudización de estos grandes problemas han participado directamente las cuatro instituciones creadas luego de la Segunda Guerra Mundial: FMI, BM, GATT = OMC y Naciones Unidas. Si estas cuatro instituciones internacionales no han cumplido con sus objetivos fundacionales hay que preguntar si existe una causa o un fenómeno común a estas cuatro crisis o quiebras globales. ¿Quiénes presiden, controlan y fijan el orden del día en estas cuatro instituciones mundiales? Los mismos actores con distinto uniforme.

\section{El malestar se gesta en las políticas del FMI-BM y de la OMC}

Podemos decir que a lo largo del siglo XX ha existido un doble Fondo Monetario Internacional. El primero se crea en 1945 luego de la crisis económica mundial de 1930. "En su concepción original, el FMI se basó en el reconocimiento de que los mercados a menudo no funcionaban; podían dar lugar a un paro masivo y fallarían a la hora de aportar fondos imprescindibles para que los países pudieran recomponer sus economías". Los países destinatarios o beneficiarios del primer FMI son los países europeos dislocados por la crisis económica y debilitados por la segunda guerra mundial. A partir de 1945 estos países asientan su desarrollo en dos modelos económicos intermedios, Economía Social de Mercado y Estado Social de Bienestar. Economías mixtas, a modo de 'terceras vías' entre la economía de libre mercado, sometida a repetidas crisis, y los modelos centralizados del nacional-socialismo o del comunismo soviético. "En la mayoría de Europa occidental tuvieron lugar en aquellos años progresos igualitarios en la distribución de la riqueza y en el control económico a través de diversas formas de economías mixtas, así como una notable expansión y perfeccionamiento de la política asistencial, facilitado todo ello por unos índices de crecimiento excepcionalmente altos”. (Tom Bottomore) Lo que olvida decir este 'admirador' 
(desde las izquierdas) es que fueron precisamente estos modelos los que planearon y lograron esos índice de crecimiento excepcionalmente altos, que no cayeron del cielo.

Conviene repetir que se trata de economías mixtas, con elevada participación del Estado (inspiración keynesiana) y planificación indicativa, concertada de antemano. (Entorno económico mundial. UCA. Editores, 2005; pp. 42-58) Una vez rehechas sus economías -Kondratief de alza 1945-1972 - estos gobiernos europeos pasan a ser grandes accionistas con elevado poder de voto y de veto en el directorio del FMI. "El FMI ha cambiado profundamente a lo largo del tiempo. Fundado en la creencia de que los mercados funcionan muchas veces mal, ahora proclama la supremacía del mercado con fervor ideológico”. Este cambio se origina en la década de los ochenta, en la era de Ronald Reagan y Margaret Thatcher, que predican e imponen la ideología del libre mercado en Estados Unidos y en el Reino Unido. El FMI y el BM imponen estas ideas y políticas a los países pobres y emergentes que requieren préstamos de estas instituciones. J. Stiglitz comenta cómo al interior del $\mathrm{BM}$ se dio un cambio de guardia, una purga del grupo de economistas preocupados por el desarrollo de los países pobres (R. McNamara, Chenery y su equipo), sustituidos por otros economistas que veían en el mercado la solución a los problemas de la pobreza.

Con la caída del Muro de Berlín se amplía el campo de acción del FMI para guiar a estos países hacia economías de mercado. A modo de anécdota, M. Gorbachov comenta los efectos adversos de la economía de libre mercado en la Rusia de su sucesor Boris Yeltsin. "El liberalismo salvaje, estimulado por las instituciones financieras internacionales, ha engendrado un gran número de crisis económicas, como ha sucedido, por ejemplo, en el Sudeste asiático, Argentina y en Rusia. Rusia le ha mostrado claramente al mundo cuál es el precio de ser un "alumno ejemplar" de las concepciones liberales de la economía en un país carente de instituciones democráticas sólidas y tradición de un capitalismo de 'rostro humano'. En menos de diez años, la población rusa ha sido saqueada y arruinada tres veces. También disminuyeron en el país la esperanza de vida y la natalidad, y apareció un fenómeno como el de las hordas de niños abandonados, lacra que desconocíamos desde los años de la guerra civil, y ello cuando Rusia ingresó en el mercado mundial, siendo un país dueño de un elevado potencial industrial, habitado por una población que gozaba de un alto nivel de instrucción y poseedor 
de vastísimos recursos naturales. Otros muchos países, arrastrados al proceso de la globalización, se han visto mucho más desprotegidos ante este fenómeno". (“Carta a la Tierra”; cfr. Realidad 2006, pp. 29-30)

A la inmensa Rusia se une nuestro continente. Nuevas medidas se agregan al "Consenso" con ocasión de los problemas surgidos en América Latina, "donde gobiernos, que habían logrado elevadas tasas de crecimiento luego de la Segunda Guerra Mundial, perdieron el control presupuestario y sus políticas monetarias se tradujeron en inflaciones rampantes, debidas — supuestamente- a la excesiva intervención estatal en la economía. El recorte de la función estatal se aplicó como receta al resto de países. La orientación keynesiana del FMI, que subrayaba los fallos del mercado y el papel del Estado en la creación de empleos, fue reemplazada por la sacralización del libre mercado en los ochenta como parte del nuevo 'Consenso de Washington' — entre el FMI, BM y el Tesoro de EE.UU. sobre las políticas 'correctas' para los países subdesarrollados-que marcó un enfoque completamente distinto del desarrollo económico y la estabilización. La liberalización de los mercados de capitales fue propiciada a pesar del hecho de que no existen pruebas de que estimule el crecimiento económico".

Importa conocer con quiénes dialogan los directorios de estas instituciones internacionales. "En el FMI son los ministros de Hacienda y los gobernadores de los bancos centrales. En la OMC son los ministros de comercio. Cada uno de estos ministros se alinea estrechamente con grupos particulares en sus propios países”. Es lógico que los ministros de comercio reflejen el pensamiento del sector empresarial, tanto exportadores como productores; los unos tratando de mantener barreras comerciales y los otros subsidios estatales. Estas peticiones pasarán a los respectivos Congresos o Asambleas, "los ministros de Hacienda y los gobernadores de los bancos centrales suelen estar muy vinculados con la comunidad financiera; no sorprende que las políticas de las instituciones económicas internacionales se ajusten demasiado a menudo en función de intereses comerciales y financieros de los países industrialmente avanzados".

"Sin alternativas, sin vías para expresar su inquietud, para instar a un cambio, la gente se alborota. Es evidente que las calles no son el sitio para discutir cuestiones, formular políticas o anudar compromisos. Pero las protestas han hecho que los funcionarios y los economistas de todo el mundo reflexionen sobre las alternativas a las políticas del Consenso 
de Washington en tanto que única y verdadera vía para el crecimiento y el desarrollo. Queda muy claro, no sólo para los ciudadanos corrientes sino también para quienes elaboran políticas, y no sólo en los países en desarrollo sino también en los desarrollados, que la globalización tal como ha sido puesta en práctica no ha conseguido lo que sus partidarios prometieron que lograría... En algunos casos ni siquiera ha logrado crecimiento, y cuando lo ha hecho, no ha proporcionado beneficios a todos; el efecto neto de las políticas estipuladas por el Consenso de Washington ha sido favorecer a las minorías a expensas de la mayoría, a los ricos a expensas de los pobres. En muchos casos los valores e intereses comerciales han prevalecido sobre las preocupaciones acerca del medio ambiente, la democracia, los derechos humanos y la justicia social”. (El malestar en la globalización; pp. 37-48).

En el presente año la crítica mundial, representada en el Foro Internacional de los Pueblos, ha bombardeado las "torres gemelas" del FMI y BM. Se les acusa de triple delito: las imperiales medidas de seguridad con que rodean sus reuniones anuales (este año en Singapur) y que sirven a poner barreras al diálogo con representantes de las ONG y de la sociedad civil. En segundo lugar se critica al BM porque enarbola la bandera de la lucha contra la corrupción y se critica al FMI por una reforma interna, que no cambia nada. Más de 700 personas, de 25 países y 100 organizaciones han participado en este foro alternativo. Se han compartido las visiones sobre temas como la Deuda Ilegítima, la condicionalidad del FMI-BM, el problema de la corrupción-transparencia y otros. "Encontramos al Banco Mundial y al FMI responsables de las políticas y acciones que traen la intensificación de la pobreza y pauperización de las condiciones de vida, la violación de los derechos humanos básicos, la restricción de las libertades políticas y civiles más básicas, la expropiación de la soberanía nacional de los pueblos y de la gobernabilidad democrática, y la subversión del derecho al desarrollo”.

Paul Wolfowitz, segundo de a bordo en el Pentágono y decidido impulsor de la guerra contra Irak, es el actual presidente del Banco Mundial, a petición y presión del presidente Bush. Wolfowitz ha impuesto su nueva Estrategia de Gobernabilidad y Anticorrupción, que ha recibido bastantes críticas. Se ha hecho público que "el Banco ofrecía amnistía y confidencialidad total a aquellas empresas que admitieran voluntariamente haber estado implicadas en casos de soborno y corrupción. Aquellas que no se acojan a esta oferta y sean descubiertas

\section{7}


entran a formar parte de una lista negra y no pueden volver a trabajar con el BM". La crítica se centra en el hecho de que el Banco Mundial carece de legitimidad e incluso de capacidad para convertirse en un árbitro imparcial en este tema. La historia del Banco está manchada por numerosos casos internos de corrupción y por el apoyo de la institución a regímenes notoriamente corruptos como los de Mobutu en el Zaire, Marcos en Filipinas, Suharto en Indonesia o Pinochet en Chile. El mismo sistema de toma de decisiones en el Banco dista mucho de lo que podemos considerar buena gobernanza.

Similar es la crítica al FMI por el anuncio de "una reforma que no cambia nada". Se desea dar mayor poder de voto a China, México, Turquía y Corea del Sur; con ello, "la reducción del poder de los países más ricos en el FMI pasa del $60 \%$ de los votos a un 59\%. Mientras, los países africanos en su conjunto pueden llegar a pasar de un ínfimo 0,5\% de los votos a un todavía minoritario 6,5\% en el futuro. Es evidente que la reforma no supone ningún cambio en la enorme desigualdad en el reparto del poder en el FMI (y de paso en el BM, que muy probablemente adoptará las mismas medidas en un futuro próximo)" (“¿Qué han dejado, un año más, las reuniones anuales del Banco Mundial y del FMI?", Rebelión, 27 de septiembre de 2006). "El FMI ha dado un primer paso hacia la adecuación de la distribución del poder de decisión en sus órganos de gobierno a los profundos cambios que han tenido lugar en la economía y en las finanzas internacionales en las dos últimas décadas. Desde su creación en 1944, el voto está determinado por las cuotas de los países socios, y éstas por una fórmula de rígida composición, en la que la magnitud del PIB de cada uno es uno de los factores importantes". ("Más vale tarde”. El País, 21 de septiembre de 2006)

Igualmente avasalladora e imperial ha sido la historia del libre comercio y de la institución que dice regularlo, la Organización Mundial del Comercio (OMC). En el foro económico mundial de Davos, de enero de 2001, la ecologista Vandana Shiva afirmó que el actual proceso de globalización, especialmente las barreras que imponen los países ricos a los productos agrícolas de los más miserables constituyen un "genocidio en una escala que la humanidad nunca ha conocido". El Premio Nóbel de Economía, J. Stiglitz usa repetidas veces la palabra "hipocresía”, luego de afirmar que el libre comercio en poco o en nada ha beneficiado a los países en desarrollo y que "la teoría del libre comercio es un fraude intelectual”. 
Para los 40.000 manifestantes en la cumbre de Seattle, que tuvo lugar en 1999, "la OMC es la Babilonia del segundo milenio, una especie de siniestra organización de rostro anónimo, convertida en el motor de una globalización que sólo favorece a las grandes multinacionales". Los manifestantes dicen estar en la calle "para dar la palabra a aquellos que jamás la han tenido y para que la OMC escuche la voz de los ciudadanos”. Los delegados de los países en desarrollo se negaron a firmar un documento final que ni siquiera habían tenido tiempo de leer.

El programa de la OMC en Doha-Qatar destila dulces promesas. "El comercio internacional puede desempeñar una función de importancia en la promoción del desarrollo económico y en el alivio de la pobreza. La mayoría de los miembros de la OMC son países en desarrollo. Pretendemos poner sus necesidades e intereses en el centro del Programa de Trabajo adoptado en la presente declaración. Reconocemos la particular vulnerabilidad de los países menos adelantados y las dificultades estructurales especiales con que tropiezan en la economía mundial. Estamos comprometidos a hacer frente a la marginación de los países menos adelantados en el comercio internacional y a mejorar su participación efectiva en el sistema multilateral de comercio". Se programan las discusiones de puntos que pueden ser más espinosos: agricultura, servicios, acceso a mercados de productos no agrícolas, derechos de propiedad intelectual, comercio e inversiones, transparencia y facilitación del comercio... Nos comprometemos a realizar reducciones de todas las formas de subvenciones a la exportación, con miras a su reducción progresiva, y reducciones sustanciales de la ayuda interna causante de distorsión del comercio". (Realidad, 2006; p. 236)

A la hipocresía se une el cinismo. Dos años más tarde, en el mes de septiembre de 2003, en la OMC de Cancún, R. Zoellick (EE.UU.) y P. Lamy (UE) dicen al grupo de los veinte (G-20): “¿qué nos ofrecen ustedes para que nosotros les ofrezcamos algo?”. Las ayudas y subvenciones internas se habían multiplicado y se corta el diálogo en Cancún. Dos años después, diciembre 2005, la OMC de Hong Kong se reduce a un diálogo entre sordos: "Si los países en desarrollo desean que los países industrializados reduzcan las ayudas y subvenciones masivas a sus exportaciones, los países emergentes deben reducir sus aranceles a las importaciones industriales que vienen del Norte y abran sus servicios a la competencia extranjera”. El día en que se inicia esta cumbre J. Stiglitz escribe un artículo: "La Ronda del desarrollo que nunca existió” y 
termina con esta conclusión: "Es probable que muchos países en vías de desarrollo lleguen a la conclusión de que es mejor no llegar a un acuerdo que aceptar un mal acuerdo, especialmente uno tan injusto como el anterior" (El País, 13 de diciembre de 2005). Los mismos actores con distinto uniforme.

De acuerdo al título y al deseo del presente comentario abro un breve espacio al discurso que el presidente de Estados Unidos hiciera en la apertura de la Cumbre del Milenio. A cinco meses de dejar la Casa Blanca, Bill Clinton sale en defensa de las Naciones Unidas. Su discurso fue interpretado como un "testamento diplomático", que serviría de apoyo a la petición de Kofi Annan: que los 154 miembros aprobaran la reforma de la ONU. Sin embargo, en este discurso de Clinton hay algo más interesante, si recordamos cómo se llevó a cabo la guerra SerbiaKosovo, 1998, sin solicitar la autorización del Consejo de Seguridad de la ONU. Este discurso es importante por cuanto sirve a recordar que algunos estatutos que habían sido firmados por la Administración Clinton fueron inmediatamente rechazados por G. W. Bush.

"Aquellos que en mi país, o en cualquier otra parte, creen que podemos prescindir de la ONU o imponer nuestra voluntad sobre ella, malinterpretan la historia y no comprenden el futuro... Nos guste o no, somos cada vez más interdependientes. Debemos buscar soluciones y alejarnos de aquellas opciones en las que se exige la total derrota de alguien”. Clinton afirmó que "la ONU debía protagonizar la lucha contra las guerras, la pobreza y la enfermedad y encabezar el esfuerzo por dotar de educación a todos los niños. La lucha por la paz, el bienestar y la salud en la aldea global tiene una etiqueta con un precio y todos los países, incluido Estados Unidos, tienen que pagarlo". "Clinton se despide de la política mundial con una vigorosa defensa de las Naciones Unidas”. El País, 7 de septiembre de 2000).

\section{La luna llena y la luna menguante de la ONU}

En el último quinquenio se ha hecho continua referencia a los objetivos del milenio, cuyos análisis concretos, a escala nacional y regional, sirven de base para evaluar el índice de desarrollo humano de los diversos países y regiones. Estos objetivos aparecen detallados en los ocho acápites y 32 artículos de la Declaración del Milenio; conviene recordar su origen histórico. Nacen de una secuencia de cumbres que Naciones 
Unidas organiza en la década de los noventa, cuando aparecen con mayor claridad los efectos políticos, sociales, económicos y ecológicos gestados en la era de la globalización. A esta secuencia de cumbres mundiales la podemos contemplar como la fase de luna llena de Naciones Unidas. En 1989 cae el Muro de Berlín y en diciembre de 1991 se firma la disolución de la URSS, del pacto de Varsovia y del CAEM. Terminaría así la era de la guerra fría para dar inicio a la paz violenta, cuando el neoliberalismo se presenta como 'el fin de la historia'.

En 1992 tiene lugar en Río de Janeiro la "Cumbre de la Tierra”, actualizando los problemas que ya se habían presentado en el Informe del Club de Roma, 1972, y que volverán a aparecer en la Cumbre del Desarrollo Sostenible, tenida en Johannesburgo, agosto 2002. Los artículos 21-23 de la Declaración del Milenio detallan los compromisos de la "Protección de nuestro entorno común". "La mitigación de los efectos de los cambios climáticos” era parte de la agenda de la LX Asamblea de Naciones Unidas, celebrada en septiembre de 2005, pero ha vuelto a quedar en la vía muerta. (ECA 2005, pp.862-863)

En 1993, la ONU organiza en Viena la "Cumbre de los Derechos Humanos”, a que hacen referencia los numerales 24 y 25 de la Declaración del Milenio. En el discurso de despedida Koffi Annan recuerda que la defensa de los derechos humanos era uno de los tres grandes desafíos cuando fue elegido Secretario General de la ONU, 1997, pero "los acontecimientos de estos diez años no los han resuelto sino que los han agudizado”. No sin razón el mensaje de Juan Pablo II en la Jornada Mundial de la Paz de 1999, tenía este lema: "El secreto de la verdadera paz reside en el respeto de los derechos humanos”. En 1994, en El Cairo, tiene lugar la cumbre sobre el "Crecimiento Demográfico" que pesa sobre los países en desarrollo cuando la losa del servicio de la deuda externa y las asimetrías del comercio internacional impiden a estos países dedicar los fondos imprescindibles a la inversión social en educación, salud, vivienda y capacitación técnica de la mano de obra activa.

En la línea de los objetivos del milenio se esperaba que tuviera gran impacto la "Cumbre sobre el Desarrollo Social", tenida en Copenhague, Dinamarca 1995, cuyo lema era: "Las sociedades prósperas son las que existen en función del ser humano". Sin embargo, los documentos de antecedentes desembocan en tres grandes problemas: "la pobreza se ha generalizado, disminuye el empleo productivo y crece la insolidaridad social”. Los datos recogidos por Naciones Unidas son lacerantes, pero 
la cumbre llegó, pasó y pocos han celebrado su aniversario. ECA le dedicó su editorial de marzo 2005: "Cómo erradicar la pobreza de la humanidad". "La contradicción principal de la cumbre radica en que, por un lado, dice que quiere erradicar la pobreza; pero por el otro, no puede desembarazarse del esquema neoliberal”.

En 1996 la ONU convoca en Beijing, China, la "Cumbre de los Derechos de la Mujer", punto central de los objetivos del Milenio, numerales 20 y 25. China no es ningún modelo de respeto a los derechos humanos de los obreros en sus empresas nacionales ni de los derechos humanos de las mujeres que laboran en las actuales maquilas. Toda la problemática sobre los derechos de la mujer vuelve a discutirse, con más ardor, en el foro social mundial tenido en Bombay, India, enero 2004. En este foro los derechos de la mujer india, "ciudadana de segunda categoría”, se enlazan con los delitos que debe juzgar la Corte Penal Internacional. Amal Basha, presidenta de la organización de los derechos humanos de Yemen, explicó que en el mundo árabe la lucha por los derechos humanos es algo muy minoritario y casi exclusivo de las mujeres. "El mundo árabe, dijo, está caracterizado por la cultura opresiva que margina sistemáticamente a gran parte de la población y especialmente a las mujeres, con el pretexto de la sharia” (ley islámica). La Premio Nóbel de la Paz, la iraní Shirin Ebani, recordó a las mujeres iraquíes "que sufrieron abusos y discriminación masivos durante el régimen de Saddam Hussein" y que, según ella, "no han visto todavía mejorar su situación durante la ocupación norteamericana. Los derechos humanos no pueden importarse por las armas", afirmó. (Entorno económico mundial, 2005; pp. 294-296)

La oficina de Naciones Unidas en El Salvador ha publicado, a modo de fuelle manual, un resumen de los Objetivos del Milenio, con un breve detalle de cada objetivo, que pueda servir de pauta para una discusión e investigación nacional. 1) Erradicar la extrema pobreza y el hambre. 2) Lograr la enseñanza primaria universal. 3) Promover la igualdad entre los géneros y la autonomía de la mujer. 4) Reducir la mortalidad infantil. 5) Mejorar la salud materna. 6) Combatir el VIH/SIDA, el paludismo y otras enfermedades. 7) Garantizar la sostenibilidad del medio ambiente. 8) Fomentar una asociación mundial para el desarrollo. Estos puntos sirven de agenda para las investigaciones que aparecen en los Informes sobre Desarrollo Humano a escala nacional, regional y mundial. 
Conviene recordar que, entonces y ahora, el objetivo fundacional de Naciones Unidas, 1945, es "la paz, la seguridad y el desarme". El artículo $1^{\circ}$ del capítulo I ${ }^{\circ}$ de la Carta de Naciones Unidas dice: "Los propósitos de las Naciones Unidas son: 1.- Mantener la paz y la seguridad internacionales y, con tal fin: tomar medidas colectivas eficaces para prevenir y eliminar amenazas a la paz, y para suprimir actos de agresión u otros quebrantamientos de la paz; y lograr por medios pacíficos, y de conformidad con los principios de la justicia y del derecho internacional, el ajuste o arreglo de controversias o situaciones internacionales susceptibles de conducir a quebrantamientos de la paz”... Está demasiado reciente la paz endeble que el Consejo de Seguridad ha logrado imponer en el conflicto israelo-libanés y la guerra siempre inconclusa israelo-palestina. En ambos casos Naciones Unidas ha demostrado ante el mundo entero que se ha dejado dominar por las grandes potencias. Esta conducta es la que actualiza la fase menguante de Naciones Unidas. ("La lucha palestina: silencio y complicidad internacional”. ECA 2006; pp.236-251)

Una hipótesis de trabajo, muy triste pero quizás bastante real, es que el gobierno de Estados Unidos (y países amigos) ha logrado anteponer el objetivo fundacional de la ONU (la paz, la seguridad y el desarme), interpretado unilateralmente, por encima del resto de los objetivos del milenio. G. W. Bush califica los ataques terroristas del 11 de septiembre como "la primera Guerra del siglo XXI", que se convierte en el problema número uno del tercer milenio. Dos meses después en la reunión de Naciones Unidas, noviembre 2001, Bush se dirige a la Asamblea General y urge a la ONU a sumarse a la batalla contra el terrorismo. "Toda una generación tiene hoy el deber de acabar para siempre con una amenaza planetaria. Quien no se sume a esta lucha pagará las consecuencias. Ha llegado el tiempo de la acción”.

A imagen y semejanza de lo que ocurrirá en tantas cumbres mundiales le corresponderá a Koffi Annan corregir el unilateralismo de G. W. Bush, poniendo sobre el tapete los otros problemas recogidos en la Cumbre del Milenio. "Estamos tentados de concentrar todas nuestras energías en la lucha contra el terrorismo, pero eso sería conceder la victoria a los terroristas, porque los problemas a que nos habíamos enfrentado el 10 de septiembre no han cambiado, sino que se hacen más urgentes. Para evitar un enfrentamiento entre las civilizaciones es necesario dar una esperanza real a millones de personas acuciadas por la pobreza, los conflictos y las enfermedades". 
La LX Asamblea General de Naciones Unidas, que se celebró en septiembre de 2005, resultó una cumbre decepcionante. En el orden del día estaban, uno a uno, los principales objetivos del milenio, pero los grandes diarios preanunciaban el fracaso. "La cumbre de la ONU concluye con resultados modestos y numerosas discrepancias". "La ONU o la Babel necesaria. La soberanía de los 191 países marca los límites a las reformas necesarias y pendientes de Naciones Unidas" (El Pais, 17 y 18 de septiembre de 2005) "Los líderes mundiales aprueban una tímida reforma de la ONU en la clausura de la cumbre". (El Mundo, 17 de septiembre de 2005) "La difícil reforma de Naciones Unidas" (Le Figaro, 14 de septiembre de 2005) "El plan de reforma preparado por la ONU es muy limitado". "Luchar contra la pobreza requiere una reforma de la ONU". (Le Monde, 14 y 18 de septiembre de 2005) Los dos temas que absorbieron el tiempo y la atención de los delegados más importantes fueron la definición de terrorismo, presentada por asesores de la ONU, y el programa del enriquecimiento de uranio que desarrolla el Gobierno de Irán, que sigue intranquilizando un año después. (ECA 2005; pp. 855-865)

\section{La LVIII cumbre de Naciones Unidas: preguntas sin respuestas}

A los tres años de la Declaración del Milenio, Kofi Annan quiere sondear el avance que hayan podido lograr las reformas planteadas en aquella cumbre; se habla de una "reforma radical" para salvar la ONU. Esta Asamblea General tiene lugar en el mes de septiembre 2003, a los seis meses de haberse iniciado la cuestionada guerra contra Irak. Los actores de este fraudulento conflicto tratarán de torcer el brazo de los otros 188 delegados miembros para que firmen una resolución final que transforme una fuerza ocupante en fuerza internacional y autorizada por Naciones Unidas. El cinismo y la inmoralidad no tienen límites y dejan sin respuesta seis importantes preguntas: “¿Para qué sirven las Naciones Unidas si no logra que se respeten sus resoluciones? ¿Cuál es la representación del Consejo de Seguridad y cuáles los criterios que le permitan decidir el uso de la fuerza? ¿Hay que conservar el derecho al veto? ¿Habrá que pensar en trasladar la sede de la ONU fuera de Nueva York? ¿Cuál es la responsabilidad de la comunidad internacional cuando un Estado no protege a sus ciudadanos? Los ciudadanos ¿deben estar representados en la ONU? (Entorno económico mundial, 2005; pp. 270-279) No se trata de responder sino de hacer un comentario a estas preguntas. 
¿Para qué sirven las Naciones Unidas si no logra que se respeten sus resoluciones? Con ocasión del largo e inconcluso conflicto bélico de Israel contra Palestina y Líbano muchos autores se han hecho esta pregunta. Cité antes a Adolfo Pérez Esquivel: "Naciones Unidas fue avasallada por las grandes potencias y la usan cuando responde a sus intereses y no a las necesidades de la humanidad. Es necesaria una reforma profunda, democratizar sus estructuras y hacerla más operativa y eficaz en bien de los pueblos”. (ECA 2006, p. 742) Augusto Zamora, profesor de derecho internacional, afirma: "Ahora Israel amenaza con destruir Líbano y anuncia ataques contra Siria. Al mismo tiempo sigue construyendo un muro, declarado ilegal por la Corte Internacional de Justicia, y pisotea las resoluciones de Naciones Unidas que le mandan volver a las fronteras de 1967, internacionalmente reconocidas" (Ibídem p. 743).

"Israel ostenta el record histórico de incumplimientos de resoluciones de Naciones Unidas, después del apartheid sudafricano. Las resoluciones incumplidas se cuentan por docenas, siendo las más conocidas la 242, que exige la retirada de Israel a las fronteras de 1967, pues Naciones Unidas considera inadmisible adquirir territorios por medio de la guerra, y la 194 sobre el derecho de los refugiados palestinos de la guerra de 1948 a retornar. Otras resoluciones exigen desmantelar los asentamientos de los colonos en los territorios de Cisjordania, Gaza y Jerusalén; poner fin a la expropiación de tierras a los palestinos; y la condena de la anexión unilateral de Jerusalén al Estado de Israel. Ninguna de estas resoluciones ha sido cumplida, lo cual pone en entredicho la autoridad del Consejo de Seguridad de Naciones Unidas. ¿Dónde está el celo de Washington y Londres para imponer al sionismo el cumplimiento de las resoluciones que lo obligan a retirarse de los territorios ocupados" (Ibidem, p. 751).

¿Cuál es la representación del Consejo de Seguridad y cuáles los criterios que le permiten decidir el uso de la fuerza?. Dos preguntas en la misma pregunta que ya se habían planteado en la Cumbre del Milenio, donde se recomendó ampliar el número de nuevos miembros del Consejo de Seguridad, pero emergen dos escollos. "Uno, el poco interés de los cinco miembros permanentes (EEUU, Rusia, China, Reino Unido y Francia) en diluir su poder con la admisión de nuevos miembros fijos. Otro, el rechazo de Rusia y China ante el derecho de injerencia. No es de extrañar que quienes abiertamente violan las libertades civiles 
rechacen el derecho de injerencia”. Ahí mismo podemos encontrar un comentario a la segunda parte de la pregunta. Koffi Annan dijo: "A menudo, los cinco países con veto culpan a la ONU de los errores que ellos provocan. Bosnia y Ruanda son sólo dos casos; nadie envió cascos azules para evitar el genocidio rwandés en 1994. Todos desoyeron al propio Secretario General de la ONU, Boutros Ghali, cuando solicitó en 1996 una policía internacional para separar asesinos de víctimas en los campos de refugiados hutus en Zaire”. Annan lamenta los múltiples fracasos de la ONU desde Bosnia-Herzegobina, 1992, Ruanda, Sierra Leona, Timor... "Esta organización se enfrenta a una grave crisis de credibilidad para llevar a cabo su principal cometido, el mantenimiento de la paz y la seguridad”.

Si en bastantes ocasiones el Consejo de Seguridad no cumplió - por omisión- con su principal objetivo, el mantenimiento de la paz y la seguridad, en otras ocasiones algunas grandes potencias han prescindido del mismo Consejo de Seguridad. Kofi Annan critica esta conducta en la apertura de la Cumbre del Milenio: "El instinto de solidaridad humana -que impulsa a algunos Estados a acudir en ayuda de los ciudadanos de otros Estados o a presentar cargos contra sus antiguos dictadores- es digno de alabanza. Pero cuando estas acciones las aplican uno o pocos Estados, en nombre de su propia autoridad, traen consigo el riesgo de la anarquía mundial”. Alusión explícita a la decisión de Estados Unidos y la OTAN de librar la guerra en Serbia-Kosovo, sin solicitar autorización del Consejo de Seguridad. Acción que se repetiría en Afganistán 2001 e Irak 2003, con la correspondiente condena de parte de Annan.

Mijail Gorbachov, actor de la Teoría de la Pacífica Coexistencia, en su libro Carta a la Tierra sale en defensa de las Naciones Unidas. "El proceso de toma de decisiones por parte de los organismos internacionales y su aplicación debe estar regido por la mayor transparencia. Y hay que pensar sobre todo en una reforma de las Naciones Unidas. Cuando hay países que se comportan como vaqueros en el salvaje Oeste, no precisan de un mandato de la ONU para emprender acciones bélicas o policiales en territorio extranjero, no cumplen las resoluciones adoptadas por una aplastante mayoría de votos, está claro que esta organización no puede seguir existiendo en su forma actual. Tal situación no es mas que una puerta abierta al caos y a los conflictos en un mundo que ha visto un inusitado auge de los más diversos nacionalismos, donde, como si se tratara de una reacción alérgica a la globalización, se multiplican

\section{6}


los síndromes arcaicos entre etnias y religiones, con explosiones de la más cruel violencia primitiva. Esto es lo que sucedió, por ejemplo, en Ruanda”.

En la agenda de la LX Asamblea General de la ONU se presentaron dos o tres alternativas de miembros componentes del Consejo de Seguridad. Sería largo y prolijo comentar las discrepancias diplomáticas que aparecen en esta cumbre. Por ejemplo, el presidente Elías Antonio Saca apoyó la candidatura de Japón, no la de Alemania, como miembro del Consejo de Seguridad. Conviene recordar que el canciller alemán, Gerhard Schröder, junto con la Francia de J. Chirac, se habían opuesto a la invasión de Irak, sin aguardar el informe de Hans Blix, jefe de inspectores de Naciones Unidas. Todos entendimos quién le soplaba a la oreja de nuestro presidente el nombre del país candidato. "Estados Unidos y China se unen para bloquear la ampliación del Consejo de Seguridad". (El País, 5 de agosto de 2005) "Se anuncia un tumultuoso debate en torno a la ampliación del Consejo de Seguridad de la ONU". (Le Monde, 11 de julio de 2005) Las fechas de estos artículos muestran que las tensiones venían de lejos.

Los juristas nos dirán si los no juristas hacemos mal en plantear la pregunta: ¿hay que conservar el derecho al veto?. Quizás estemos equivocados, pero respondemos a la pregunta con un caso concreto que se presenta cuando tiene lugar la LVIII Asamblea General de la ONU. Con fecha 14 de octubre 2003, John Negroponte, embajador de EEUU ante la ONU, impone su veto a una resolución presentada ante el Consejo de Seguridad por Siria, en nombre del grupo árabe, condenando la construcción por Israel de un "muro de seguridad en Cisjordania". El texto juzgaba que esta construcción era "ilegal, de acuerdo a las normas del derecho internacional” y solicitaba la oposición del Consejo "a todas las actividades de colonización en los territorios ocupados y de todas las actividades que impliquen la confiscación de tierras y su anexión”. Los representantes del grupo árabe han calificado esta empalizada de 150 kilómetros como "el muro expansionista de una conquista ilegal".

John Negroponte justifica su recurso al veto aduciendo que "el texto no era equilibrado y no condenaba el terrorismo en términos explícitos. Una resolución del Consejo de Seguridad que se queda en la frontera, no permite progresar en el objetivo de llegar a la paz y a la seguridad en la región”. El representante israelí afirmó que se trataba sólo de "métodos no violentos, los más eficaces para impedir el paso de los 
terroristas y de sus armas hacia las zonas civiles" israelitas. (Le Monde, 10 de octubre de 2003) ¿De qué sirve un Consejo de Seguridad si la condena avalada por el "voto" de diez de sus miembros queda anulada por un "solo veto" del representante de un país que, al igual que Israel, se destaca por burlar tradicionalmente las resoluciones de Naciones Unidas.

La historia no termina ahí. El 21 de octubre de 2003, la Asamblea General de la ONU aprobó detener la construcción del "muro de seguridad" con una mayoría aplastante de 144 votos a favor, 4 en contra (EEUU, Israel, Micronesia e Islas Marshall) y 11 abstenciones. El muro israelita "contraviene el derecho internacional" exigiendo a Israel que "cese y deshaga" la construcción porque usurpa territorios palestinos. El juicio de la Asamblea General no es vinculante, pero tiene toda la fuerza moral. En diciembre 2003 la Asamblea de Naciones Unidas traslada la solicitud a la Corte Internacional de Justicia, quien basa su argumentación sobre la noción de territorios ocupados. "De acuerdo a la resolución 242 del Consejo de Seguridad de Naciones Unidas la Corte recuerda que la construcción de colonias israelíes en tierras palestinas es ilegal por ser territorios "ocupados por la fuerza”, incluida la zona oriental de Jerusalén. La Corte internacional de Justicia afirma que "Las Naciones Unidas, en particular la Asamblea General y el Consejo de Seguridad deben presentar las medidas para poner término a la presente situación”.

El 20 de julio de 2004, la Asamblea General de la ONU ha emitido un voto apoyando la sentencia emitida por la Corte Internacional de Justicia, justificando la destrucción del 'muro de seguridad' construido por Israel (fuerza ocupante) en territorio palestino y la indemnización a los palestinos por daños causados. El voto, aprobado por 150 voces, 6 en contra (entre ellos EEUU) y 10 abstenciones, ha sido el resultado de intensas negociaciones para reiniciar el proceso de paz. Como era de esperar "Israel rechaza la resolución de la ONU que le exige derribar el muro". Esta misma problemática ha vuelto a aparecer con ocasión de la guerra entre Israel y Palestina a partir del 25 de junio 2006. ¿Para qué vale el Consejo de Seguridad si el "veto" de personas de tan escasa moralidad jurídica como John Negroponte, John Bolton y similares puede abolir los votos mayoritarios de los otros miembros del Consejo?. ¿Dónde está el "consejo" y dónde la "seguridad”? 
Hay otra razón que convierte al Consejo de Seguridad en un organismo de escasa moralidad. En la Cumbre del Milenio Koffi Annan solicitó a los países miembros ratificar los estatutos de la Corte Penal Internacional (CPI) que juzgue los crímenes de guerra, contra la paz, lesa humanidad y genocidio que los tribunales nacionales no puedan o no quieran juzgar. La Corte Penal Internacional no será retroactiva y emitirá sentencia contra delitos cometidos a partir del $1^{\circ}$ de julio de 2002. Los estatutos de la CPI han sido ratificados por 94 de los 191 países miembros. Sólo cinco de los quince países miembros del Consejo de Seguridad han aprobado estos estatutos; tres de los cinco países miembros permanentes y con poder de veto no los han ratificado: EEUU, Rusia y China. ¿Dónde está la seguridad del Consejo de Seguridad, en el respeto al derecho internacional y a los derechos humanos o en el derecho de la fuerza atómica? Esos tres Gobiernos, especialmente el de Estados Unidos y el de China, carecen de la calidad moral necesaria para seguir blandiendo el "privilegio del veto" al interior del Consejo de Seguridad de Naciones Unidas.

\section{5. "Querida ONU"}

Después de todo hago mío el titular de Le Monde, con fecha 18 de septiembre 2005, cuando dijimos a los 191 miembros delegados a la LX Asamblea General: ¿jpor qué nos han decepcionado? Las Naciones Unidas nacen en un momento difícil de la historia: un mundo golpeado por la segunda guerra mundial y dividido entre Este y Oeste, donde sigue pendiente la espada de Damocles: "si vis pacem, para bellum" (si quieres la paz, prepara la guerra: la carrera armamentística). En ese escenario se redacta la Carta de las Naciones Unidas, que vuelve a tener la misma actualidad o resonancia sesenta años más tarde. He aquí su preámbulo:

Nosotros los pueblos de las Naciones Unidas resueltos a preservar a las generaciones venideras del flagelo de la guerra, que dos veces durante nuestra vida ha infligido a la Humanidad sufrimientos indecibles, a reafirmar la fe en los derechos fundamentales del hombre, en la dignidad y en el valor de la persona humana, en la igualdad de los derechos de hombres y mujeres y de las naciones grandes y pequeñas, a crear condiciones bajo las cuales puedan mantenerse la justicia y el respeto a las obligaciones emanadas de los tratados y de otras fuentes del derecho internacional, a promover el progreso social y a elevar el nivel de 
vida dentro de un concepto más amplio de la libertad, y con tantas finalidades a practicar la tolerancia y a convivir en paz como buenos vecinos, a unir nuestras fuerzas para el mantenimiento de la paz y la seguridad internacionales, a asegurar, mediante la aceptación de principios y la adopción de métodos, que no se usará la fuerza armada sino en servicio del interés común, y emplear un mecanismo internacional para promover el progreso económico y social de todos los pueblos, hemos decidido unir nuestros esfuerzos para realizar estos designios.

Si estos fueron los designios fundacionales en 1945, queda muy claro que la institución de Naciones Unidas es igualmente necesaria en el tercer milenio. Si en ese escenario tan complejo de "un mundo crucificado" entre Este y Oeste y entre Norte y Sur hubo hombres de paz que nos hablaron de los derechos fundamentales del hombre, de la igualdad de derechos de mujeres y hombres, de las pequeñas y grandes naciones, del respeto al derecho internacional..., es necesario reformar para conservar la institución de Naciones Unidas, a no ser que admitamos que se esté dando un "proceso de involución” en la especie humana. (¿Homo homini lupus?) Si hubo desafortunados economistas que se dedicaron a divulgar la asignatura de sistemas económicos comparados "el uno contra el otro", también ha habido otros economistas pacificadores que nos enseñaron a comparar cada sistema económico "contra sí mismo": sus ideales contra sus realidades y "a remodelarlo".

En este sentido tenemos que hablar de los "cuatrillizos" gestados después de la segunda guerra mundial: el FMI, el BM, el GATT (OMC) y las Naciones Unidas. Ya que los tres primeros han fracasado escandalosamente porque se han negado a compararse "contra sí mismos", hagamos el mayor esfuerzo por salvar las Naciones Unidas. Tal vez, desde una ONU reformada podamos iniciar un proceso de salvación de los hermanos gemelos. Si quiebran las Naciones Unidas ¿dónde se van a discutir esos designios y problemas de ese Preámbulo?

El foro económico mundial de Davos es algo caro: $\$ 25.000$ por ser miembro y $\$ 6.000$ por la reunión de enero; aunque hay que decir que los temas tratados en las tres últimos foros de Davos han sido bien humanos. Las reuniones del G-8 son cada más inútiles e insulsas; basta ver la de este año en San Petersburgo, Rusia. Nadie se enteraría si las suprimen. Las cumbres del FMI y BM cada vez les ponen más barreras y policías para mantener la distancia con los problemas de la Humanidad. Nos quedaría sólo el Foro Social Mundial de Porto Alegre y Bombay. 
Pero bastantes jefes de Estado no querrán llegar hasta allí. No nos queda mas que volver a Naciones Unidas.

Entre otras personas que confían y esperan mucho de las funciones a realizar por la ONU está Mijail Gorbachov, porque al interior de la URSS trató de reformar la teoría leninista de la "coexistencia pacífica" (si quieres la paz, prepara la guerra) en la teoría de "la pacífica coexistencia”. En diciembre de 1984, encabezando una delegación del Soviet Supremo, Gorbachov pronunció un discurso ante los parlamentarios británicos: "A pesar de todo aquello que nos separa, habitamos un mismo planeta. Europa es nuestra casa común. Es precisamente eso, una casa y no un teatro de operaciones militares. En particular afirmábamos que no hay valor superior al de la vida humana, que la renuncia a la violencia debe erigirse en el principio fundacional de la coexistencia entre los individuos y los pueblos, que debe sustituir al 'equilibrio del terror' por un sistema global de seguridad internacional. En un siglo nuclear no podía haber vencedores, que las relaciones internacionales no podían seguir enmarcadas en los esquemas de la guerra fría y estábamos decididos a emprender la puesta en práctica de cualquier esquema de reducción de armamentos, especialmente del armamento nuclear, en condiciones de paridad con nuestros socios occidentales”.

Veinte años más tarde, en su Carta a la Tierra, M. Gorbachov hace una serie de propuestas desde su experiencia de gran estadista. "La ONU nació tras la segunda guerra mundial y, todavía hoy, su estructura refleja la situación generada por la victoria aliada sobre la Alemania nazi y el Japón imperialista, cuando el mundo fue dividido en vencedores y vencidos. Nada puede explicar en nuestra época, salvo aquellas circunstancias, por qué estos dos inmensos países democráticos no forman parte del Consejo de Seguridad en calidad de miembros permanentes. Considero que ha llegado el momento de suprimir el artículo 53 de la Carta de Naciones Unidas, que hace mención a los "estados hostiles". Para aumentar el peso y la influencia del Consejo de Seguridad, para democratizarlo, propongo aceptar en él como miembros permanentes a países que también gozan de una gran autoridad en la escena internacional, como India, Italia, Indonesia, Canadá, Polonia, Brasil, México, Egipto, incluso si no se les concede el derecho al veto desde el principio”.

A continuación, Gorbachov hace una propuesta que no creo sea por propio interés. "Me gustaría exponer una idea que me es muy preciada y cuya implementación ayudaría a suplir el déficit moral que padece la

\section{1}


política contemporánea. En todas las sociedades tradicionales los ancianos gozan de un gran respeto y autoridad moral. ¿Por qué no crear entonces, en el marco de la ONU un consejo de ancianos de la "aldea global”, integrado por personalidades reconocidas y respetadas del mundo de la ciencia y de la cultura, Premios Nobel, altos representantes de diferentes confesiones, eminentes hombres de Estado ya retirados? Los políticos actuales no pueden desconocer cuán necesaria es la humanización de la política”.

Gorbachov hace también una petición moral a las instituciones de Bretton Woods, en busca de una mayor democracia. "¿Cómo hacer para que la globalización redunde en beneficios para toda la humanidad?. Un objetivo tan vasto reclama ante todo una gestión global. Algunos han llegado a proponer la creación de un gobierno planetario. Considero que es un proyecto utópico, antidemocrático e, incluso, peligroso. Mejor sería incrementar y hacer más eficaz la actividad de las instituciones internacionales de las que ya disponemos —las Naciones Unidas, el Fondo Monetario Internacional, el Banco Mundial, la Organización Mundial del Comercio- dotarlas de poderes más amplios, para construir una única comunidad organizada de manera democrática, cuyos miembros sean los estados de la Tierra, todos con iguales derechos. Es muy importante que cada vez que se adopten decisiones internacionales de orden económico se tomen en cuenta, sistemáticamente, los factores ecológicos y sociales. También lo es que se establezcan las reglas para un comercio internacional justo, que sea capaz de potenciar las economías locales y contribuya a la eliminación de la pobreza. Por último, es importante que se introduzcan mecanismos como la tasa Tobin, que controlen los mercados financieros, creando de esa manera, un mecanismo efectivo que garantice el desarrollo sostenible".

Carta a la Tierra se centra en los problemas que derivan de la degradación medio ambiental, incluida la difícil solución a la creciente masa de los residuos sólidos nucleares. Necesariamente Gorbachov confía, en parte, este control al ámbito de Naciones Unidas. "Teniendo en cuenta la gravedad de los problemas de seguridad ecológica, de la frecuencia creciente de las catástrofes de origen natural o humano, me parece fundamental que se le concedan al Consejo de Seguridad plenos poderes en este ámbito. Si bien yo no soy partidario de inflar las estructuras burocráticas, encontré muy atractiva la idea del ex primer ministro francés Lionel Jospin de transformar la programa de la ONU para el 
Medio Ambiente en una organización mundial con competencias plenas. Una organización de este tipo permitiría contrarrestar la influencia de las diferentes organizaciones económicas internacionales que orientan a los países en desarrollo hacia un modelo de economía de mercado pura, unificaría las numerosas convenciones internacionales ya existentes y velaría por su cumplimiento”.

Con la idea de recomendar la lectura de Carta a la Tierra, una última cita de Mijail Gorbachov. Otra idea que no me canso de propugnar es la creación de un Tribunal Ecológico Internacional, según el modelo de la Corte Penal Internacional de La Haya, que realice, por una parte, funciones de arbitraje y, por otra, se encargue de juzgar a los países, o a empresas concretas, que sean reconocidos culpables de haber causado perjuicios al entorno o a las poblaciones. Actualmente, en efecto, no disponemos de medios jurídicos para castigar tales actos, sobre todo, paradójicamente, si la víctima es la Humanidad en su totalidad. ¿Quién impondrá sanciones a los países que, habiendo rarificado el Protocolo de Kyoto — que presupone la reducción para el año 2012 de la emisión de gases de 'efecto invernadero' - no cumplan con las obligaciones que han asumido? ¿Quién demandará a los países ricos del Norte por los daños ocasionados al entorno de los países pobres del Sur por la emisión de esos mismos gases?

Al terminar el siglo XX los asesores de Naciones Unidas habían recogido la secuencia de problemas mundiales, cuya solución se convertía en los Objetivos del Milenio. El logro de estos objetivos parece haber encontrado un difícil competidor, el llamado "terrorismo islámico" que pasa a ser el problema número uno de algunas potencias del Norte. Deducimos esta hipótesis del mismo fracaso de las LVIII y LX Asambleas Generales de Naciones Unidas, cuya orden del día - reforma de la ONU y Objetivos del Milenio- fue extraviada para centrarse en las diversas caras del poliedro terrorismo. La tensa resolución del Consejo de Seguridad sobre el conflicto bélico de Israel contra el Líbano y Palestina nos hace tomar mejor conciencia del papel fundamental que Naciones Unidas, en forma más democrática, puede y debe jugar para controlar también los terrorismos de Estado.

Al finalizar el mes de septiembre un informe preparado por 16 agencias de seguridad de Estados Unidos y un segundo informe enviado al Consejo de Seguridad, muestran que la guerra contra Irak (sin autorización de la ONU) se ha convertido "en un excelente campo de

\section{3}


entrenamiento para Al Qaeda y contribuye a reforzar el movimiento islámico armado". El número de atentados suicidas crece cada día y amenazan con repetirse en Afganistán y otros países. La Casa Blanca tiene que admitir, a regañadientes, que la invasión a Irak ha sido una pésima decisión para Estados Unidos y otros gobiernos del mundo. Este grave error debe ser pulsado y analizado con mayor sinceridad y verdad en el seno de Naciones Unidas porque amenaza la paz y la seguridad mundial y, por añadidura, hace imposible alcanzar los Objetivos del Milenio. 